\title{
Working Up Rectal Bleeding in Adult Primary Care Practices
}

Saul N. Weingart, MD, MPP, PhD ${ }^{1,2}$ Chief Medical Officer, Tufts Medical Center; Professor of Medicine, Tufts University School of Medicine

Elena M. Stoffel, MD, MPH ${ }^{3}$ Attending Physician and Assistant Professor of Medicine, University of Michigan Medical School

Daniel C. Chung, MD ${ }^{4,5}$ Clinical Chief, Gastrointestinal Unit, Massachusetts General Hospital; Associate Professor of Medicine, Harvard Medical School

Thomas D. Sequist, MD, MPH ${ }^{5,6,7}$ Chief Quality and Safety Officer, Partners Healthcare; Associate Professor of Medicine and Health Care Quality, Harvard Medical School

Ruth I. Lederman, $\mathrm{MPH}^{8}$ Survey Manager, Survey and Data Management Core, Dana-Farber Cancer Institute

Stephen R. Pelletier, $\mathrm{PhD}^{5}$ Senior Project Manager, Center for Evaluation, Harvard Medical School

Helen M. Shields, MD ${ }^{5,6}$ Associate Chief, Division of Medical Communications, Department of Medicine, Brigham and Women's Hospital; Professor of Medicine, Harvard Medical School

${ }^{1}$ Tufts Medical Center, 800 Washington St, Boston, MA, 02111, USA

${ }^{2}$ Tufts University School of Medicine, 136 Harrison Ave, Boston, MA, 02111, USA

${ }^{3}$ University of Michigan Medical School, 1500 Medical Center Dr, Ann Arbor, MI, 48109, USA

${ }^{4}$ Massachusetts General Hospital, 55 Fruit St, Boston, MA, 02114, USA

${ }^{5}$ Harvard Medical School, 25 Shattuck St, Boston, MA, 02115, USA

${ }^{6}$ Brigham and Women's Hospital, 75 Francis St, Boston, MA, 02115, USA

${ }^{7}$ Partners Healthcare System, 800 Boylston St, Boston, MA, 02199, USA

${ }^{8}$ Dana-Farber Cancer Institute, 450 Brookline Ave, Boston, MA 02115, USA

Word count: 3,088

Word count (abstract): 273

Number of references: 28

Number of tables: 4

Number of figures: 1

This is the author manuscript accepted for publication and has undergone full peer review but has not been through the copyediting, typesetting, pagination and proofreading process, which may lead to differences between this version and the Version of Record. Please cite this article as doi: 10.1111/jep.12596

This article is protected by copyright. All rights reserved. 
Keywords: rectal bleeding, practice guidelines, missed diagnosis, practice variation, medical error

Corresponding author: Dr. Weingart, Tufts Medical Center, 800 Washington St, Boston, MA 02111, tel. 01-617-636-7780, fax. 01-617-636-7623, sweingart@ tuftsmedicalcenter.org

\section{ABSTRACT}

Rationale, aims and objectives: Variation in the workup of rectal bleeding may result in guideline-discordant care and delayed diagnosis of colorectal cancer. Accordingly, we undertook this study to characterize primary care clinicians' initial rectal bleeding evaluation.

Methods: We studied 438 patients at 10 adult primary care practices affiliated with three Boston, Massachusetts, academic medical centers and a multispecialty group practice, performing medical record reviews of subjects with visit codes for rectal bleeding, hemorrhoids, or bloody stool. Nurse reviewers abstracted patients' sociodemographic characteristics and rectal bleeding-related symptoms. We calculated the percent of cases in which the clinician elicited a medical and family history of colorectal cancer or polyps, performed a physical examination, ordered laboratory, imaging, or diagnostic procedures, noted a presumptive diagnosis, discusssed rectal bleeding with the patient, or documented a follow up plan. Bivariate and multivariable logistic regression models examined factors associated with guideline-discordant workups.

Results: Clinicians documented a family history of colorectal cancer or polyps at the index visit in $27 \%$ of cases and failed to document an abdominal or rectal examination in $21 \%$ and $29 \%$. 
Failure to order imaging or a diagnostic procedure occurred in $32 \%$ of cases and was the only component of the workup associated with guideline-discordant care, which occurred in $27 \%$ of cases. Compared to hospital-based teaching sites, patients at urban clinics or community health centers had 2.9 (95\% CI 1.3-6.3) times the odds of having had an incomplete workup. Network affiliation was also associated with guideline concordance.

Conclusion: Workup of rectal bleeding was inconsistent, incomplete, and discordant with guidelines in one-quarter of cases. Research and improvements strategies are needed to understand and manage practice and provider variation.

This article is protected by copyright. All rights reserved. 
Primary care clinicians are often asked to assess the clinical significance of common complaints. Rectal bleeding is a case in point, requiring clinicians to distinguish bleeding attributable to conditions such as internal hemorrhoids from more ominous diseases like colorectal cancer. Twelve to fifteen percent of patients report seeing blood on the toilet paper in the previous six months [1]. In addition to the bleeding history and examination findings, clinicians' evaluation of rectal bleeding may be informed by attributes that affect the prior probability of malignant disease, including the patient's age, race, family history, and prior screening or diagnostic studies. And though professional practice guidelines outline the elements of a recommended evaluation [2], few take into account the subtlety or complexity of cases that present themselves to frontline practitioners. This leads to variation in practice, guidelinediscordant care, and delayed diagnosis [1-5].

In order to understand variation in the workup of rectal bleeding, we undertook a secondary analysis of a medical record review study of patients over 40 years of age with rectal bleeding cared for at 10 Boston adult primary care practices [6]. The present study seeks to characterize primary care providers' initial evaluation of rectal bleeding and the degree to which variation in the workup of rectal bleeding accounted for differences in practice guideline concordance. We hypothesized that the workup of rectal bleeding and guideline concordance would vary substantially by practice site.

\section{METHODS}




\section{Setting}

We studied 10 adult primary care practices associated with three Harvard-affiliated Boston academic medical centers and a large multispecialty group practice. Each of the three medical centers had an onsite primary care teaching practice. The community practices were selected using a computer-generated random number from among the practices associated with each medical center or the multispecialty group practice. Four of the community-based practices were urban and three were suburban. All sites associated with a given medical center or group practice shared a common electronic medical record.

\section{Subjects}

Subjects were adult primary care patients who were seen in their primary care practice from 1 July 2006 to 30 June 2008 with a new episode of rectal bleeding. Potential subjects were identified using administrative records generated for each site based on age over 40 years and presence of the following ICD-9-CM codes 569.3 (rectal bleeding), 578.1 (blood in the stool), and 455.0, 455.1, 455.2 or 455.3 (hemorrhoids).

\section{Measurements}

The research team, comprised of primary care physicians, gastroenterologists, nurses, and health services researchers, created a chart abstraction instrument based on a tool used to examine the quality of breast cancer care in a primary care population [7]. The instrument 
elicited information including age, race, ethnicity, gender, primary language, insurance, home zip code, and medical co-morbidities. It also elicited information about rectal bleeding-related symptoms, medical history, physical examination and findings, diagnostic tests, specialty referrals, and communication of test results. After piloting a paper form of the tool for usability, the instrument was converted into an online data entry and storage format using Datstat (Illume, Seattle, Washington).

Investigators trained nurse reviewers in record abstraction and data entry using practice cases. The chart review entailed examination of the electronic ambulatory medical record at each site during a three-month period following an initial primary care visit for rectal bleeding (the "index" visit). Nurse reviewers checked the note from the index visit to confirm that the patient was not undergoing an evaluation for a recent episode of rectal bleeding. We excluded patients if rectal bleeding was identified in an emergency department immediately prior to the index visit or if patients had ulcerative colitis, Crohn's disease, or a history of colorectal cancer based on a 3year retrospective review of problem lists, progress and consult notes, and discharge summaries.

The research team met regularly to review data collection and ensure consistent abstraction practices across study sites. Two physician-investigators next reviewed each nurse abstraction to confirm study eligibility and to classify the adequacy of the workup and overall quality of care. The nurse abstractions were performed from 5 January 2010 to 6 April 2011, to allow for complete follow up and ascertainment of pathology results, with physician review from 26 January 2010 to 26 October 2012. 
Of 740 patients with an ICD-9 code for rectal bleeding, 480 were found to be eligible on initial review after excluding cases with prior bleeding, known colorectal cancer, or inflammatory bowel disease. Forty-two additional cases were excluded based on physician review of the nurse abstraction, yielding a final cohort of 438 subjects.

\section{Analyses}

We tabulated the sociodemographic and clinical characteristics of the cohort and and clinicians' workup of rectal bleeding. Based on medical record documentation, we calculated the number and percent of cases in which the clinician at the index visit elicited a history of present illness and family history of colorectal cancer or polyps; performed a physical examination; ordered laboratory, imaging, or diagnostic procedures; noted a presumptive diagnosis; discusssed rectal bleeding with the patient; or documented a follow up plan. We tabulated the number and percent of cases where a finding or abnormality was identified. Zip codes were used as proxy for income based on US Census data and divided into low $\left(0-49^{\text {th }}\right.$ percentile $)$, medium $\left(50-74^{\text {th }}\right)$, and high $\left(>75^{\text {th }}\right)$ income categories.

Guideline concordance was based on the Harvard Risk Management Foundation's 2006 Colon Cancer Screening and Diagnosis Guidelines [8], an evidence-based algorithm widely distributed to study practices [6-17]. The Guidelines for rectal bleeding called for a colonoscopy among patients $\geq 50$ years old with rectal bleeding and no colonoscopy in the previous two years, and among patients 40-49 years old with a family history of colon cancer or colonic 
adenomas. The Guidelines recommended at least a flexible sigmoidoscopy for patients with rectal bleeding age $\geq 50$ with a colonoscopy in the previous two years and for those age 40-49 without a family history.

We classified care as delayed if an interval of more than 90 days elapsed from index visit to completion of a procedure to visualize the colon in accordance with the Guidelines. Patients who had completed a colonoscopy with adequate preparation within two years were not considered guideline-concordant.

We examined the assocation of patients' sociodemographic, clinicial characteristics, and practice setting with the odds of having a guideline-concordant workup in bivariate analyses using the Chi-square statistic for categorical data and the Wilcoxon rank-sum test for continuous data. We created bivariate and multivariable logistic regression models using backward elimination $(\mathrm{p} \leq 0.2)$ and 2 -tailed tests of significance $(\mathrm{p} \leq 0.05)$. We repeated this approach to examine whether components of the rectal bleeding workup at the index visit were associated with guideline-concordant care, controlling for sociodemographic, clinical, and practice factors that were statistically significant in the initial model. We performed a parallel analysis to examine whether positive findings during the workup of rectal bleeding were associated with guideline-concordant care. Analyses used Stata 9 (StataCorp, College Station, TX). The study was approved in advance by the Dana-Farber/Harvard Cancer Center institutional review board.

\section{RESULTS}




\section{Patient characteristics}

Characteristics of the study cohort are displayed in Table 1 . The mean age was $56,19 \%$ were non-white, $10 \%$ were Hispanic, and $8 \%$ required an interpreter during clinic visits. Subjects' neighborhood income was below the US mean in $26 \%$ of cases, and $16 \%$ had Medicaid insurance or were self-insured. Fourteen percent had a family history of colorectal cancer or colon polyps, $32 \%$ had a prior history of any rectal bleeding, and 55\% had previously completed colorectal cancer screening. The cohort was distributed among hospital-based, urban, and suburban practice sites.

(TABLE 1 HERE)

\section{Workup of rectal bleeding}

Table 2 displays the workup of rectal bleeding at the index visit and the presence of abnormal findings. Clinicians elicited and documented information about the patient's present history of rectal bleeding in $96 \%$ of cases. Altered bowel habits were the most commonly reported symptom. Clinicians documented a positive or negative family history of colon cancer or polyps in the the index visit progress note in only $27 \%$ of patients, with about one-third of these subjects reporting a positive family history. Clinicians documented the blood pressure routinely, but reported an abdominal orrectal exam in only $79 \%$ and $71 \%$ of cases, respectively. Positive findings were present in a minority of cases. Although clinicians ordered blood counts (hemoglobin, hematocrit, or complete blood count) for every patient, less than $2 \%$ were 
abnormal. Clinicians ordered imaging or diagnostic procedures in about two-thirds of cases, including referrals to a gastroenterologist for consultation or colonoscopy in $50 \%$ of cases. Clinicians documented a presumptive diagnosis in their note in two-thirds of cases, with hemorrhoids identified most often. Clinicians documented a discussion of rectal bleeding with the patient and a follow up plan in most cases. Six colon cancers were detected among patients in this cohort.

\section{(TABLE 2 HERE)}

\section{Factors associated with guideline-discordant care}

Overall, 117 (27\%) of 438 patients with rectal bleeding failed to receive guidelineconcordant care within 90 days of the index visit. Guideline concordance, stratified by subjects' sociodemographic, clinical, and practice characteristics, is shown in Table 3.

\section{(TABLE 3 HERE)}

Practice type and network affiliation were the only factors associated with a guideline discordant workup in bivariate analyses. In the multivariable model, a personal history of prior colorectal cancer screening increased the odds of an incomplete workup by 1.6 (95\% CI 1.02.7). Compared to patients seen at hospital-based teaching sites, those seen at urban clinics or community health centers were 2.9 (1.3-6.3) times as likely to have had an incomplete workup after controlling for other covariates. Network affiliation also was associated with guideline 
concordance. Patients in Network C had an increased odds (2.2, 1.0-4.9) and those in Network D a decreased odds $(0.1,0.0-0.4)$ of an incomplete workup.

Given the prominence of practice type and network affiliation on the workup of rectal bleeding, we examined guideline-discordance by practice, as shown in the Figure. Performance varied markedly from site to site within each network, although discordant care and practice variation were notably less prominent in Network D compared to the others.

\section{(FIGURE HERE)}

Controlling for the sociodemographic, clinical, and practice factors associated with guideline-discordant workup, we examined whether components of the clinicans' workup at the index visit were associated with guideline-discordant care. As shown in Table 4, ordering of an imaging or diagnostic procedure and documentation of a follow up plan were the only factors associated with reduced odds of a guideline-discordant workup in bivariate analyses. In the multivariable analysis, ordering an imaging or diagnostic test was the only factor with decreased odds of guideline-discordant care $(0.4,0.2-0.6)$. In a parallel analysis examining the relationship between positive findings at the index visit and guideline concordance, failure to complete imaging or diagnostic testing increased the odds of guideline-discordant care by 5.9 (3.5-9.9).

\section{(TABLE 4 HERE)}

\section{DISCUSSION}


We found significant variation in the workup of rectal bleeding in this retrospective record review of 438 patients cared for at 10 Boston adult primary care practices, including worrisome lapses. Clinicians working up symptoms of rectal bleeding rarely documented that a family history of colorectal cancer or polyps was performed at the index visit, and many failed to describe an abdominal or rectal examination. Clinicians ordered blood counts and hemoglobin levels routinely, but rarely found evidence of anemia. Although most clinicians documented a discussion of the findings with the patient and a follow up plan, they failed to specify a presumptive or differential diagnosis one-third of the time. No order for additional diagnostic testing such as flexible sigmoidoscopy or colonoscopy was made in $32 \%$ of cases. Failure to order additional testing or imaging occurred in about one in four cases. It was the only component of the workup that was associated reliably with guideline-discordant care in the multivariable analysis, since the guideline explicitly required timely diagnostic testing or imaging. .

Variation in care is a well-known phenomenon in health care, often seen when the evidence base for best practice is thin [9-11]. Absent consensus about appropriate care, clinicians rely on their own judgement and experience, and benchmark their practice against colleagues and peers. Practice guidelines can reduce variation and improve standardization, but dissemination and implementation of guidelines is challenging and often protracted [12-14]. Colorectal cancer screening guidelines are a case in point. In regional and national practitioner surveys conducted over the past decade, primary care physicians' knowledge of colorectal cancer screening 
guidelines was inconsistent [15-18]. Studies have demonstrated knowledge and performance deficits with respect to colorectal cancer screening, with variation in performance associated with factors such as patient age, comorbid illness, and provider specialty [19-20].

Organizational factors played a prominent role in this study, with marked variation in the workup of rectal bleeding and guideline concordance across practices, practice types, and networks. This finding mirrors research showing the importance of practice-related influence in colorectal cancer screening and in surveillance colonoscopy for colorectal cancer survivors [21]. For example, a survey of 984 Arizona primary care physicians showed significantly lower rates of self-reported colorectal screening guideline compliance among solo, group, and community health center-based clinicians compared to those in academic practice [18]. Similarly, a study of 38,818 patients at 155 Veterans Administration clinics showed an association of colorectal cancer screening rates with the operational characteristics of the clinic, such as control over care processes, smaller size, and support resources [22]. Electronic health records can improve the likelihood of guideline compliance with colorectal cancer screening, but may not overcome persistent patterns of interpractice variation [23].

Unfortunately, we have little evidence to explain why certain practices in this study performed so much better than others. All sites used electronic medical records, although the utility and usability of the systems may differ. Urban practices and community health centers may lack resources available to other practice types. The multivariable models controlled for multiple potential confounders, suggesting that unmeasured factors such as clinic protocols, 
operational standards, information technology, and practitioner alignment may have produced more practice discipline at some sites than others. It is possible that certain practices were better resourced than others in terms of staffing or performance improvement expertise, or that the organizational culture of the organization or practice affected the collective performance of that unit. In fact, these factors are likely more important than individual physician performance and documentation. A similar phenomenon has been reported across cancer centers, where disesase management decisions across institutions reflected local and historical approaches to common clinical scenarios [11]. In addition, patients' willingness or inability to comply with clinicians' recommendations may play a prominent role.

While rectal bleeding is a familiar complaint facing primary care clinicians, its evaluation may be quite challenging and nuanced. Of the patients in our study, one in seven had a family history of colorectal cancer or colon polyps, one-third had a personal history of recent rectal bleeding, and more than half had previously undergone colon cancer screening. This complexity is not readily incorporated into practice guidelines. Primary care physicians may question the relevance of a practice guideline that calls for repeated colonoscopy in a patient with persistent bleeding and multiple prior negative workups [24].

At the same time, failure to identify a serious illness represents a potentially serious diagnostic error. Previous investigators have reported that alarm symptoms are often unrecognized among patients ultimately diagnosed with colorectal cancer, implying that clinicians could have identified and referred such cases earlier for testing and treatment. Missed 
and delayed colorectal cancer diagnoses are a large and growing source of malpractice liability claims [25]. Increased prominence of these claims reflects a variety of factors including patients' rising expectations for early detection. It belies the burden of morbidity and early mortality for patients with delayed colorectal cancer diagnoses, financial consequences and emotional impact for patients and families, and risk to the relationship between patients and their health providers. Improving the care of patients with rectal bleeding requires practitioners to adopt a disciplined approach to the evaluation of worrisome clinical signs. Although clinician education is a no-regret strategy, initiatives are more likely to succeed if they address practice infrastructure. For example, practices should facilitate access to diagnostic algorithms for rectal bleeding and embed decision support in electronic health records. Templated notes may prompt clinicians to perform a thorough assessment and ensure complete documentation of symptoms and signs, family history, examination findings, and differential diagnosis. Standard order-sets may simplify laboratory testing and facilitate referrals for endoscopic imaging. However, successful adoption of innovations requires buy-in from practitioners and their staffs. Without a culture that values reliability as a mechanism for reducing variability and improving quality, efforts to standardize care may become "tick-box" exercises that add little value [26-27].

This study was limited by the use of retrospective medical record review, a process that requires consistent data abstraction and is dependent upon the quality of documentation. We attempted to overcome this limitation by using well trained nurse reviewers and a standardized online data collection tool. The study was not powered to assess the impact of lapses on clinical 
outcomes such as cancer-specific mortality or stage at diagnosis. However, our outcome measure required timely completion of the evaluation. Delays are a patient-centered outcome that may correlated with unnecessary emotional distress. In addition, the study's generalizability may be limited by the selection of Boston practices affiliated with large healthcare systems. The clinical care in these organizations may be more consistent than care delivered in other communities, in turn, underestimating the degree of variation of care present elsewhere. Finally, the findings may be limited by the time interval that has elapsed since the care was rendered. While practice changes at the study sites may have occurred since the data were collected, the CRICO Guidelines for workup of rectal bleeding have undergone only one minor modification: colonoscopy is now recommended as an alternative to flexible sigmoidoscopy for rectal bleeders over age 50 whose last colonoscopy occurred more than two years earlier[28].

In summary, rectal bleeding is a common complaint in primary care and one that must be evaluated carefully to rule out polyps, cancer, or other serious conditions. Frontline clinicians' task may be complicated by the prevalence of this complaint in primary care practice and in the same patient, common benign alternative diagnoses such as internal hemorroids, and physicians' reluctance to recommend an invasive diagnostic test such as colonoscopy. Given the potential malpractice liability associated with misssed colorectal cancer diagnoses, clinicians are advised to complete and document a thorough initial assessment including a family history of gastrointestinal polyps or cancer, abdominal and rectal examinations, and presumptive diagnoses. Referral for definitive testing is the single, critical component of the workup 
associated with guideline-concordant care. Additional invesigation is necessary to understand why certain practices or practice networks are more likely than others to provide consistent guideline-concordant care.

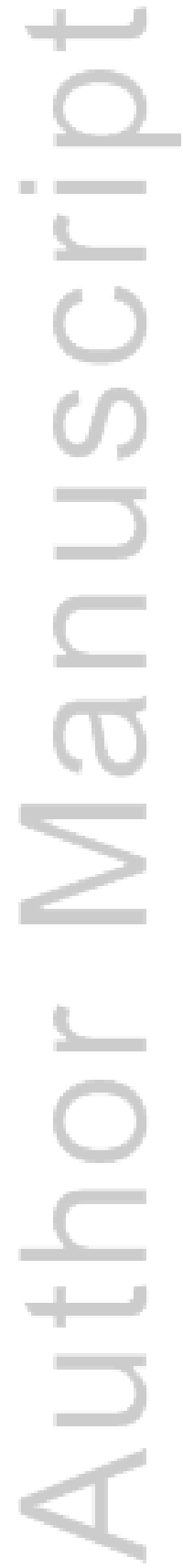

This article is protected by copyright. All rights reserved. 


\section{ACKNOWLEDGEMENTS}

Contributors. The authors wish to acknowledge Megan Sweeney, BS, Tufts Medical Center, for her contributions related to data analysis, which were compensated in her role as research assistant. Dr. Weingart had full access to all of the data in the study and takes responsibility for the integrity of the data and the accuracy of the data analysis.

\section{Author contributions:}

Conception or design: Weingart, Stoffel, Chung, Sequist, Lederman, Pelletier, Shields Acquisition, analysis, or interpretation of data: Weingart, Stoffel, Chung, Sequist, Lederman, Pelletier, Shields

Drafting of the manuscript: Weingart

Critical revision of the manuscript: Stoffel, Chung, Sequist, Lederman, Pelletier, Shields

Statistical analysis: Weingart, Pelletier

Obtaining funding: Weingart, Shields

Administrative, technical, or material support: Weingart, Stoffel, Chung, Sequist, Lederman,

Pelletier, Shields

Supervision: Shields

Funding Acknowledgments. This study was funded in part by a grant from the Risk Management Foundation of the Harvard Medical Institutions. The sponsor had no role in design 
and conduct of the study; collection, management, analysis, and interpretation of the data; and preparation, review, or approval of the manuscript.

Declaration of Conflicting Interests. The authors report no conflicts of interest. This paper was not previously presented.

\section{REFERENCES}

1. Jones, R., Latinovic, R., Charlton, J., Gulliford, M. (2007) Alarm symptoms in early diagnosis of cancer in primary care: cohort study using General Practice Research Database. BMJ, 334(7602), 1040.

2. CRICO/RMF Colorectal Cancer Screening Algorithm: A Decision Support Tool. (2010) Cambridge, MA: CRICO/Risk Management Foundation.

3. Ellis, G., Thompson, R. (2005) Factors identifying higher risk rectal bleeding in general practice. British Journal of Medical Practice, 55(521), 949-955.

4. Dozois, E., Boardman, L., Suwanthanma, W., Limburg, P., Cima, R., Bakken, J., Vierkant, R., Aakre, J., Larson, D. (2008) Young-onset colorectal cancer in patients with no known genetic predisposition. Medicine, 87(5), 259-263.

5. Winawer, S. (2003) Colorectal cancer screening and surveillance: Clinical guidelines and rationale? Update based on new evidence. Gastroenterology, 124(2), 544-560.

6. Shields, H., Stoffel, E., Chung, D., et al. (2014) Disparities in evaluation of patients with rectal bleeding 40 years and older. Clinical Gastroenterology and Hepatology, 12(4), 669-675.

This article is protected by copyright. All rights reserved. 
7. Weingart, S., Saadeh, M., Simchowitz, B., Gandhi, T., Nekhlyudov, L., Studdert, D., Puopolo, A., Shulman, L. (2009) Process of care failures in breast cancer diagnosis. Journal of General Internal Medicine, 24(6), 702-709.

8. Risk Management Foundation Colon Cancer Screening and Diagnosis Guidelines. (2006). Cambridge, MA: CRICO/Risk Management Foundation.

9. Leape L. (1993) The appropriateness of use of coronary artery bypass graft surgery in New York State. Journal of the American Medical Association, 269(6), 753-760.

10. Kahan, J., Park, R., Leape, L., Bernstein, S., Hilborne, L., Parker, L., Kamberg, C., Ballard, D., Brook, R. (1996) Variations by specialty in physician ratings of the appropriateness and necessity of indications for procedures. Medical Care, 34(6), $512-$ 523.

11. Weeks, J., Uno, H., Taback, N., Ting, G., Cronin, A., D'Amico, T., Friedberg, J., Schrag, D. (2014) Interinstitutional variation in management decisions for treatment of 4 common types of cancer: A multi-institutional cohort study. Annals of Internal Medicine, 161(1), 20-30.

12. Rogers, M. Lessons for guidelines from the diffusion of innovations. (1995) Joint Commission Journal on Quality Improvement, 21(7), 324-328.

13. Davis, A., Taylor-Valsey, A. Translating guidelines into practice: A systematic review of theoretic concepts, practical experience and research evidence in the adoption of practice guidelines. (1997) Canadian Medical Association Journal, 157(4), 408-416. 
14. Cabana, M., Rand, S., Powe, R., Wu, W., Wilson, H., Abboud, Y., Rubin, R. (1999) Why don't physicians follow clinical practice guidelines? A framework for improvement. Journal of the American Medical Association, 282(15), 1458-1465.

15. Klabunde, C., Frame, P., Meadow, A., Jones, E., Nadel, M., Vernon, S. (2003) A national survey of primary care physicians colorectal cancer screening recommendations and practices. Preventive Medicine, 36(3), 352-362.

16. McGregor, S., Hilsden, R., Murray, A., Bryant, H. (2004) Colorectal cancer screening: Practices and opinions of primary care physicians. Preventive Medicine, 39(2), 279-285.

17. Yabroff, K., Klabunde, C., Yuan, G., McNeel, T., Brown, M., Casciotti, D., Buckman, D., Taplin, S. (2010) Are physicians' recommendations for colorectal cancer screening guideline-consistent? Journal of General Internal Medicine, 26(2), 177-184.

18. Nodora, J., Martz, W., Ashbeck, E., Jacobs, E., Thompson, P., Martunez, M. (2011) Primary care physician compliance with colorectal cancer screening guidelines. Cancer Causes \& Control, 22(9), 1277-1287.

19. Haggstrom, D., Klabunde, C., Smith, J., Yuan, G. (2012) Variation in primary care physicians' colorectal cancer screening recommendations by patient age and comorbidity. Journal of General Internal Medicine, 28(1), 18-24.

20. Higgins, B., Doubeni, A., Phillips, K., Laiyemo, A., Briesacher, B., Tjia, J., Doubeni, C. (2012) Self-reported colorectal cancer screening of Medicare beneficiaries in family 
medicine vs. internal medicine practices in the United States: A cross-sectional study. BMC Gastroenterology, 12(1), 23.

21. Salz, T., Weinberger, M., Ayanian, J., Brewer, N., Earle, C., Elston Lafata, J., Fisher, D., Weiner, B., Sandler, R. (2010) Variation in use of surveillance colonoscopy among colorectal cancer survivors in the United States. BMC Health Services Research, 10(1), 256.

22. Yano, E., Soban, L., Parkerton, P., Etzioni, D. (2007) Primary care practice organization influences colorectal cancer screening performance. Health Services Research, 42(3), 1130-1149.

23. Ornstein, S., Nemeth, L., Jenkins, R., Nietert, P. (2010) Colorectal cancer screening in primary care. Medical Care, 48(10), 900-906.

24. Kruse, G., Khan, S., Zaslavsky, A., Ayanian, J., Sequist, T. (2014) Overuse of colonoscopy for colorectal cancer screening and surveillance. Journal of General Internal Medicine, 30(3), 277-283.

25. Hoffman, J. (2014) Annual Benchmarking Report: Malpractice Risk in the Diagnostic Process. Available at: http://www.rmfstrategies.com/ /media/Files/Strategies/Reports/crico_benchmarking_am bdx final.pdf. Accessed 6 March 2016.

This article is protected by copyright. All rights reserved. 
26. Urbach, D., Govindarajan, A., Saskin, R., Wilton, A., Baxter, N. (2014) Introduction of surgical safety checklists in Ontario, Canada. The New England Journal of Medicine, 370(11): 1029-1038.

27. Leape, L. (2014) The checklist conundrum. The New England Journal of Medicine, 370(11): 1063-1064.

28. CRICO. Prevention and Early Detection of Colorectal Cancer. Cambridge, MA: CRICO, 2014. Available at:

https://www.rmf.harvard.edu/ /media/Files/_Global/KC/PDFs/Guidelines/crico_cca_201 4_locked.pdf. Accessed Mar 31, 2016.

This article is protected by copyright. All rights reserved. 
FIGURE LEGEND

Figure. Percent of subjects with guideline-discordant workup of rectal bleeding within 90 days, by network (A, B, C, D) and practice site

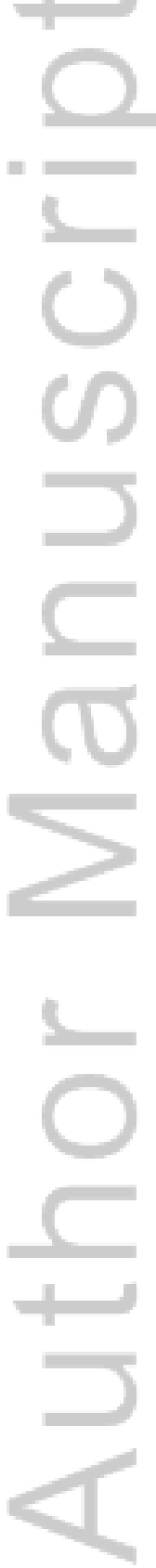

This article is protected by copyright. All rights reserved. 
Table 1. Subjects' social, demographic, clinical, and practice characteristics, $\mathbf{N}=\mathbf{4 3 8}$

\begin{tabular}{|c|c|}
\hline Age, mean (range), SD & $56.4(40-93), 12.1$ \\
\hline Male, $\mathrm{n}(\%)$ & $188(42.9)$ \\
\hline \multicolumn{2}{|l|}{ Race, n (\%) } \\
\hline White & $278(63.5)$ \\
\hline African American & $62(14.2)$ \\
\hline Asian & $20(4.6)$ \\
\hline American Indian or Alaska native & $1(0.2)$ \\
\hline Unknown & $77(17.6)$ \\
\hline \multicolumn{2}{|l|}{ Ethnicity, n (\%) } \\
\hline Hispanic & $43(9.8)$ \\
\hline Non-Hispanic & $376(85.8)$ \\
\hline Unknown & $19(4.3)$ \\
\hline Interpreter required, $\mathrm{n}(\%)$ & $36(8.2)$ \\
\hline Lived alone, $\mathrm{n}(\%)$ & $80(18.3)$ \\
\hline \multicolumn{2}{|l|}{ Neighborhood income vs. US mean, n (\%) } \\
\hline$<50 \%$ & $115(26.3)$ \\
\hline $50-74 \%$ & $86(19.6)$ \\
\hline$>74 \%$ & $237(54.1)$ \\
\hline \multicolumn{2}{|l|}{ Insurance, $\mathrm{n}(\%)$} \\
\hline Private & $241(55.0)$ \\
\hline Medicare & $119(27.2)$ \\
\hline Medicaid or self-pay & $72(16.4)$ \\
\hline Federal & $2(0.5)$ \\
\hline Unknown & $4(0.9)$ \\
\hline Charlson index, mean (range), SD & $0.6(0-8), 1.1$ \\
\hline Number of medications, mean (range), SD & $4.9(0-26), 4.3$ \\
\hline $\begin{array}{l}\text { Family history of colorectal cancer or colon polyps in first } \\
\text { degree relatives, } \mathrm{n}(\%)\end{array}$ & $61(13.9)$ \\
\hline Personal history of rectal bleeding in previous three years, n (\%) & $139(31.7)$ \\
\hline Personal history of any prior colon cancer screening ${ }^{*}, \mathrm{n}(\%)$ & $267(54.6)$ \\
\hline \multicolumn{2}{|l|}{ Practice type, $\mathrm{n}(\%)$} \\
\hline Hospital-based teaching site & $163(37.2)$ \\
\hline Urban practice or community health center & $142(32.4)$ \\
\hline Suburban practice & $133(30.4)$ \\
\hline \multicolumn{2}{|l|}{ Network, n (\%) } \\
\hline $\mathrm{A}$ & $65(14.8)$ \\
\hline $\mathrm{B}$ & $185(42.2)$ \\
\hline $\mathrm{C}$ & $79(18.0)$ \\
\hline
\end{tabular}

This article is protected by copyright. All rights reserved. 


\begin{tabular}{|l|c|}
\hline $\mathrm{D}$ & $109(24.9)$ \\
\hline Identified nurse practitioner, $\mathrm{n}(\%)$ & $40(9.1)$ \\
\hline
\end{tabular}

$\mathrm{SD}$, standard deviation

"Prior screening tests included colonoscopy ( $\mathrm{n}=237)$, stool occult blood ( $\mathrm{n}=92)$, flexible sigmoidoscopy $(\mathrm{n}=67)$, barium enema $(\mathrm{n}=7)$, or virtual colonoscopy $(\mathrm{n}=3)$.

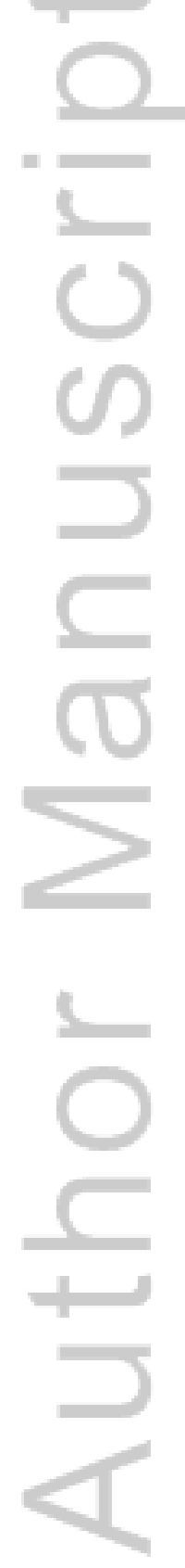

This article is protected by copyright. All rights reserved. 
Table 2. Workup of rectal bleeding at the index visit and findings, $N=438$

\begin{tabular}{|c|c|c|}
\hline & $\begin{array}{l}\text { Assessment } \\
\text { Performed } \\
\text { n/N, \% }\end{array}$ & $\begin{array}{c}\text { Abnormality or } \\
\text { Finding Present } \\
\mathrm{n} / \mathrm{N}, \%\end{array}$ \\
\hline \multicolumn{3}{|l|}{ History of present illness elicited } \\
\hline Any history elicited & $420 / 438,95.9$ & $299 / 420,71.2$ \\
\hline $\begin{array}{l}\text { Bowel habits (i.e., bleeding, easy, hard, normal } \\
\text { stool, straining) }\end{array}$ & $326 / 438,74.4$ & $207 / 326,63.5$ \\
\hline Diarrhea & $284 / 438,64.8$ & $57 / 284,20.1$ \\
\hline Rectal pain & $307 / 438,70.1$ & $80 / 307,26.1$ \\
\hline Abdominal pain & $336 / 438,76.7$ & $50 / 336,14.9$ \\
\hline $\begin{array}{l}\text { Other associated symptoms (i.e., chills, fever, loss } \\
\text { of appetite, weight loss, other) }\end{array}$ & $343 / 438,78.3$ & $70 / 343,20.4$ \\
\hline Family history of colon cancer or polyps elicited & $116 / 438,26.5$ & $35 / 116,30.2$ \\
\hline \multicolumn{3}{|l|}{ Physical examination performed } \\
\hline $\begin{array}{l}\text { Blood pressure taken (abnormal if systolic blood } \\
\text { pressure }<100 \mathrm{~mm} \text { ) }\end{array}$ & $395 / 438,90.2$ & $8 / 395,2.0$ \\
\hline $\begin{array}{l}\text { Abdominal exam (abnormal if pain, tenderness, } \\
\text { distension, hepatomegaly, or other finding was } \\
\text { present) }\end{array}$ & $347 / 438,79.2$ & $35 / 347,10.1$ \\
\hline Rectal exam & $310 / 438,70.8$ & $53 / 310,17.1$ \\
\hline Fecal occult blood test & $228 / 438,52.1$ & $80 / 228,35.1$ \\
\hline Vaginal exam (women only) & $40 / 250,16.0$ & $0 / 40,0$ \\
\hline \multicolumn{3}{|l|}{ Laboratory testing performed } \\
\hline $\begin{array}{l}\text { Any blood tests (i.e., hemoglobin, hematocrit, INR, } \\
\text { or iron studies) }\end{array}$ & $438 / 438,100.0$ & $8 / 438,1.8$ \\
\hline Hemoglobin or hematocrit & $438 / 438,100.0$ & 4/438, 0.9 \\
\hline INR & $12 / 438,2.7$ & $0 / 12,0$ \\
\hline $\begin{array}{l}\text { Iron studies (i.e., iron, ferritin, or total iron binding } \\
\text { capacity) }\end{array}$ & $25 / 438,5.7$ & $5 / 25,20.0$ \\
\hline $\begin{array}{l}\text { Imaging or diagnostic procedure ordered/not } \\
\text { completed }\end{array}$ & 298/438, 68.0 & $58 / 298,19.5$ \\
\hline Presumptive diagnosis noted $^{\dagger}$ & $288 / 438,65.8$ & $\mathrm{n} / \mathrm{a}$ \\
\hline Rectal bleeding discussed with patient & $415 / 438,94.7$ & $\mathrm{n} / \mathrm{a}$ \\
\hline Follow up plan documented & $372 / 438,84.9$ & $\mathrm{n} / \mathrm{a}$ \\
\hline
\end{tabular}

SD, standard deviation; INR, international normalized ratio; n/a, not applicable

*Completed imaging procedures included colonoscopy $(n=218)$, upper endoscopy $(n=14)$, flexible sigmoidoscopy ( $n=9)$, abdominal CT scan $(n=8)$, anoscopy $(n=7)$, barium enema $(n=1)$, or virtual colonoscopy $(n=1)$.

This article is protected by copyright. All rights reserved. 
${ }^{\dagger}$ Presumptive diagnoses at the initial visit included hemorrhoids $(n=205)$, colon polyp $(n=22)$, anal fissure $(n=21)$, colon cancer $(n=14)$, diverticulosis $(n=19)$, arterial-venous malformation $(n=9)$, infectious colitis $(n=3)$, ulcerative colitis $(n=3)$, anal fistula $(n=1)$, Crohn's disease $(n=2)$, other diagnosis $(n=70)$; totals may exceed $100 \%$ because clinicians may have identified multiple diagnoses in a given case.

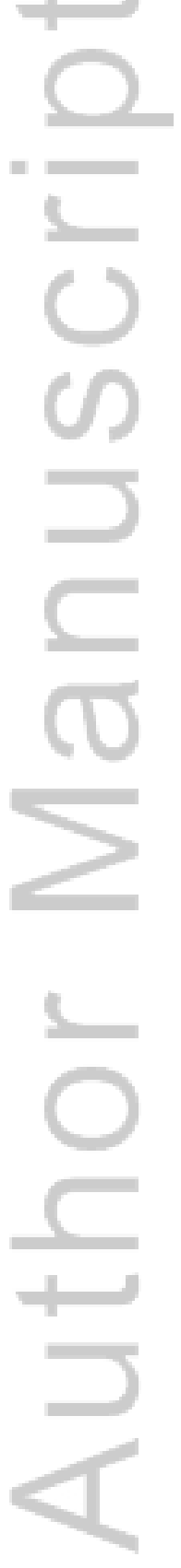

This article is protected by copyright. All rights reserved. 
Table 3. Subjects' social, demographic, clinical, and practice characteristics and their association with guideline-discordant workup for rectal bleeding within 90 days, $N=438$

\begin{tabular}{|c|c|c|c|c|c|}
\hline Characteristic, \% & $\begin{array}{c}\text { Concordant } \\
\text { care }(n=321)\end{array}$ & $\begin{array}{c}\text { Discordant } \\
\text { care }(\mathrm{n}=117)\end{array}$ & P-value & $\begin{array}{c}\text { Bivariate } \\
\text { (unadjusted) } \\
\text { OR }(95 \% \mathrm{CI})\end{array}$ & $\begin{array}{l}\text { Multivariable } \\
\left.\text { (adjusted*) }^{*}\right) \\
\text { OR }(95 \% \mathrm{CI}) \\
\end{array}$ \\
\hline Age, mean (range), SD & $\begin{array}{c}56.3(40-93), \\
12.0\end{array}$ & $\begin{array}{c}56.2(40-88), \\
12.3\end{array}$ & $0.97 \mathrm{rs}$ & $1.000(0.983-1.018)$ & -- \\
\hline Male gender & 43.9 & 40.2 & 0.48 chi & $0.857(0.557-1.318)$ & -- \\
\hline Non-white race & 22.6 & 24.2 & 0.74 chi & $1.097(0.632-1.901)$ & -- \\
\hline Hispanic & 11.4 & 7.2 & $0.22 \mathrm{chi}$ & $0.606(0.272-1.349)$ & -- \\
\hline Interpreter required & 8.4 & 7.7 & $0.81 \mathrm{chi}$ & $0.907(0.413-1.991)$ & -- \\
\hline Lived alone & 17.8 & 19.7 & $0.65 \mathrm{chi}$ & $1.133(0.661-1.941)$ & -- \\
\hline Neighborhood income v. US mean & & & $0.93 \mathrm{chi}$ & & \\
\hline$<50 \%$ & 26.5 & 25.6 & -- & Ref & -- \\
\hline $50-74 \%$ & 19.9 & 18.8 & -- & $0.974(0.514-1.844)$ & -- \\
\hline$>74 \% \cup$ & 53.6 & 55.6 & -- & $1.071(0.646-1.774)$ & -- \\
\hline Medicaid or self-insured & 5.6 & 8.6 & $0.27 \mathrm{chi}$ & $1.573(0.704-3.515)$ & -- \\
\hline Charlson index, mean (range), SD & $0.6(0-6), 1.1$ & $0.7(0-8), 1.3$ & $0.36 \mathrm{rs}$ & $1.064(0.890-1.272)$ & -- \\
\hline $\begin{array}{l}\text { Number of medications, mean (range), } \\
\text { SD }\end{array}$ & $4.9(0-19), 4.1$ & $5.3(0-26), 5.1$ & $0.97 \mathrm{rs}$ & $1.017(0.970-1.068)$ & -- \\
\hline $\begin{array}{l}\text { Family history of colorectal cancer or } \\
\text { colon polyps }\end{array}$ & 41.5 & 10.6 & $0.14 \mathrm{chi}$ & $0.624(0.335-1.163)$ & $0.792(0.418-1.500)$ \\
\hline $\begin{array}{l}\text { Personal history of rectal bleeding in } \\
\text { the previous } 3 \text { years }\end{array}$ & 68.3 & 31.7 & $0.46 \mathrm{chi}$ & $0.993(0.630-1.565)$ & -- \\
\hline $\begin{array}{l}\text { Personal history of prior colon cancer } \\
\text { screening }\end{array}$ & 44.3 & 55.7 & $0.16 \mathrm{chi}$ & $1.340(0.893-2.010)$ & $1.569(1.044-2.729)$ \\
\hline Practice type & & & $0.001 \mathrm{chi}$ & & \\
\hline
\end{tabular}

This article is protected by copyright. All rights reserved. 
Working up Rectal Bleeding

\begin{tabular}{|l|c|c|c|c|c|}
\hline Hospital-based teaching site & 41.4 & 25.6 & -- & Ref & Ref \\
\hline $\begin{array}{l}\text { Urban practice or community health } \\
\text { center }\end{array}$ & 32.7 & 31.6 & -- & $2.892(1.243-6.725)$ & $2.913(1.340-6.335)$ \\
\hline Suburban practice & 25.9 & 42.7 & -- & $1.836(0.972-3.466)$ & $1.744(0.976-3.146)$ \\
\hline Network & & & $<0.001$ chi & & \\
\hline A & 15.6 & 12.8 & -- & Ref & Ref \\
\hline B & 40.8 & 46.2 & -- & $1.252(0.558-2.811)$ & $1.540(0.763-3.108)$ \\
\hline C & 11.8 & 35.0 & -- & $2.756(1.131-6.712)$ & $2.188(0.969-4.941)$ \\
\hline D & 31.8 & 6.0 & -- & $0.110(0.037-0.331)$ & $0.135(0.048-0.381)$ \\
\hline Identified nurse practitioner & 9.7 & 7.7 & 0.53 chi & $0.779(0.359-1.691)$ & - \\
\hline
\end{tabular}

OR, odds ratio; CI, confidence interval; chi, Chi-square statistic; rs, rank-sum test

*Step-wise logistic regression with backward elimination $(\mathrm{P} \leq 0.2)$

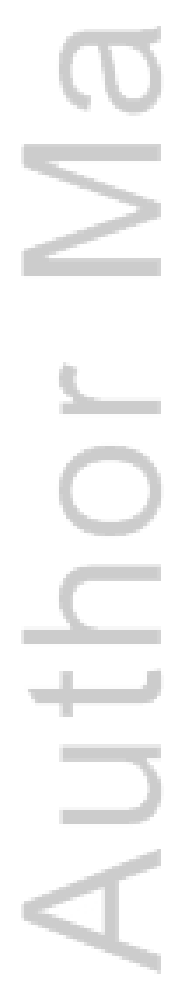

This article is protected by copyright. All rights reserved. 
Table 4. Workup of rectal bleeding at the index visit and its association with guideline-discordant workup for rectal bleeding within 90 days, $\mathrm{N}=438$

\begin{tabular}{|c|c|c|c|c|c|c|}
\hline$=$ & $\begin{array}{c}\text { Concordant } \\
\text { care } \\
(n=321), \%\end{array}$ & $\begin{array}{l}\text { Discordant } \\
\quad \text { care } \\
(\mathrm{n}=117), \%\end{array}$ & P-value & $\begin{array}{c}\text { Bivariate } \\
\text { (unadjusted) } \\
\text { OR }(95 \% \mathrm{CI})\end{array}$ & $\begin{array}{c}\text { Multivariable } \\
\left.\text { (adjusted }^{*}\right) \\
\text { OR }(95 \% \text { CI) } \\
\text { Finding Elicited }\end{array}$ & $\begin{array}{c}\text { Multivariable } \\
\left.\text { (adjusted }^{*}\right) \\
\text { OR (95\% CI) } \\
\text { Finding Present }\end{array}$ \\
\hline \multicolumn{7}{|c|}{$\begin{array}{l}\text { Any history of present } \\
\text { illness }\end{array}$} \\
\hline Elicited & 73.3 & 26.7 & 0.92 chi & $0.945(0.330-2.712)$ & $9.90(1.027-95.451)$ & \\
\hline Positive & 75.9 & 24.1 & $0.07 \mathrm{chi}$ & $0.662(0.425-1.032)$ & & $0.684(0.421-1.111)$ \\
\hline \multicolumn{7}{|c|}{$\begin{array}{l}\text { Family history of colon } \\
\text { cancer or polyps }\end{array}$} \\
\hline Elicited & 75.0 & 25.0 & $0.63 \mathrm{chi}$ & $0.886(0.545-1.442)$ & $1.393(0.828-2.341)$ & \\
\hline Positive & 77.1 & 22.9 & $0.59 \mathrm{chi}$ & $0.799(0.352-1.813)$ & & -- \\
\hline \multicolumn{7}{|l|}{ Blood pressure } \\
\hline Taken & 72.2 & 27.9 & $0.10 \mathrm{chi}$ & $1.985(0.858-4.593)$ & -- & \\
\hline Abnormal & 62.5 & 37.5 & $0.49 \mathrm{chi}$ & $1.663(0.391-7.071)$ & & $3.979(0.695-22.768)$ \\
\hline \multicolumn{7}{|c|}{ Abdominal exam } \\
\hline Performed & 73.2 & 26.8 & 0.94 chi & $1.022(0.606-1.724)$ & $0.550(0.237-1.273)$ & \\
\hline Abnormal & 82.9 & 17.1 & $0.18 \mathrm{chi}$ & $0.544(0.220-1.346)$ & & -- \\
\hline \multicolumn{7}{|l|}{ Rectal exam } \\
\hline Performed & 71.6 & 28.4 & $0.22 \mathrm{chi}$ & $1.353(0.836-2.191)$ & -- & \\
\hline Abnormal & 66.7 & 33.3 & $0.24 \mathrm{chi}$ & $1.439(0.782-2.650)$ & & -- \\
\hline \multicolumn{7}{|c|}{ Fecal occult blood test } \\
\hline Performed & 70.6 & 29.4 & $0.19 \mathrm{chi}$ & $1.332(0.869-2.040)$ & $1.754(0.894-3.440)$ & \\
\hline Positive & 72.5 & 27.5 & $0.86 \mathrm{chi}$ & $1.050(0.610-1.809)$ & & $1.491(0.910-2.443)$ \\
\hline Vaginal exam & 70.0 & 30.0 & $0.76 \mathrm{chi}$ & $1.123(0.535-2.356)$ & $\mathrm{n} / \mathrm{a}$ & $\mathrm{n} / \mathrm{a}$ \\
\hline
\end{tabular}

This article is protected by copyright. All rights reserved. 


\begin{tabular}{|c|c|c|c|c|c|c|}
\hline \multicolumn{7}{|l|}{$\begin{array}{l}\text { performed (women } \\
\text { only, } n=281 \text { ) }\end{array}$} \\
\hline \multicolumn{7}{|l|}{ Laboratory testing } \\
\hline $\begin{array}{l}\text { Any blood test } \\
\text { performed }\end{array}$ & 100.0 & 100.0 & $\mathrm{n} / \mathrm{a}$ & $\mathrm{n} / \mathrm{a}$ & $\mathrm{n} / \mathrm{a}$ & \\
\hline Abnormal & 50.0 & 50.0 & $0.13 \mathrm{chi}$ & $\begin{array}{l}2.805(0.690- \\
11.404)\end{array}$ & & $3.979(0.695-22.77)$ \\
\hline \multicolumn{7}{|l|}{$\begin{array}{l}\text { Imaging or diagnostic } \\
\text { procedure }\end{array}$} \\
\hline Any test ordered & 80.2 & 19.8 & $\begin{array}{l}<0.001 \\
\text { chi }\end{array}$ & $0.349(0.225-0.542)$ & $0.352(0.200-0.618)$ & \\
\hline Testing not completed & 58.1 & 41.9 & $\begin{array}{l}<0.001 \\
\text { chi }\end{array}$ & $4.373(2.761-6.925)$ & & $5.863(3.462-9.928)$ \\
\hline $\begin{array}{l}\text { Presumptive diagnosis } \\
\text { noted }\end{array}$ & 74.0 & 26.0 & 0.66 chi & $0.905(0.581-1.141)$ & -- & $\mathrm{n} / \mathrm{a}$ \\
\hline $\begin{array}{l}\text { Rectal bleeding } \\
\text { discussed with patient }\end{array}$ & 73.3 & 26.8 & 0.94 chi & $1.035(0.398-2.690)$ & -- & $\mathrm{n} / \mathrm{a}$ \\
\hline $\begin{array}{l}\text { Follow up plan } \\
\text { documented }\end{array}$ & 76.3 & 23.7 & $0.001 \mathrm{chi}$ & $0.395(0.230-0.680)$ & $0.580(0.292-1.154)$ & $\mathrm{n} / \mathrm{a}$ \\
\hline
\end{tabular}

OR, odds ratio; chi, CI, confidence interval; Chi-square statistic.

*Step-wise logistic regression with backward elimination $(\mathrm{P} \leq 0.2)$, controlling for social, demographic, clinical, and practice factors included in the multivariable model in Table 3.

${ }^{\dagger}$ Assessments included bowel habits, diarrhea, rectal pain, abdominal pain, or other specified symptoms as listed in Table 2.

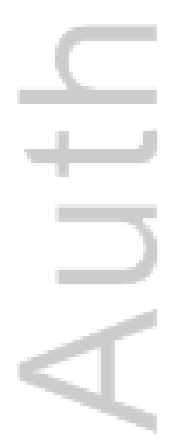

This article is protected by copyright. All rights reserved. 
${ }^{\ddagger}$ Blood tests included hemoglobin, hematocrit, complete blood count, international normalized ratio, iron, ferritin, total iron binding capacity as listed in Table 2 .

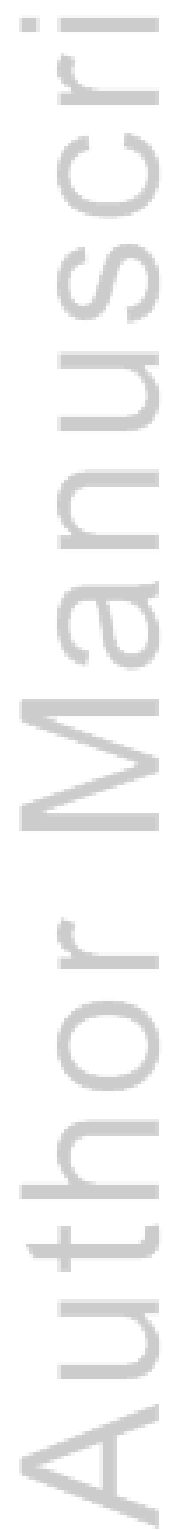

This article is protected by copyright. All rights reserved. 


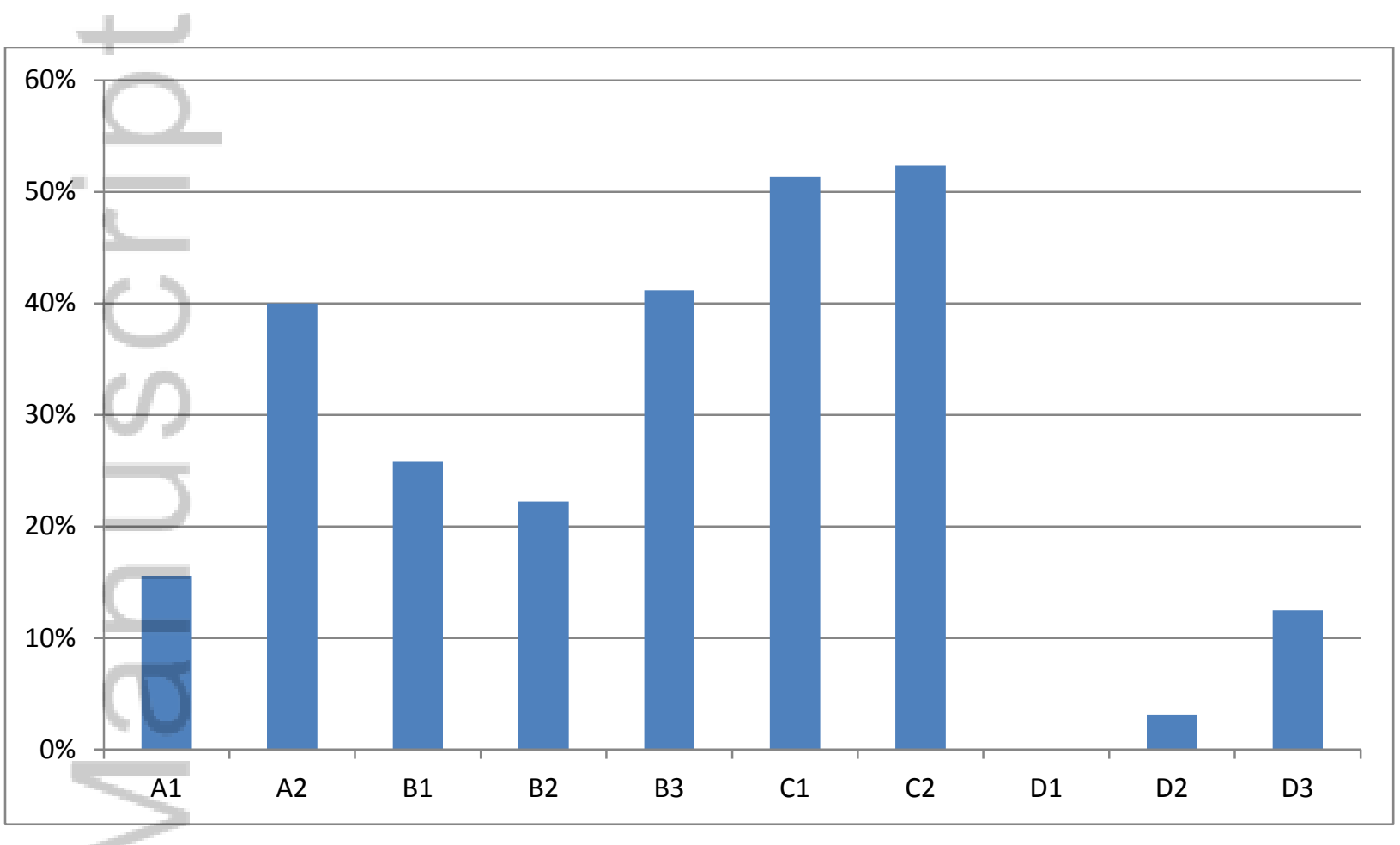

This article is protected by copyright. All rights reserved. 